\title{
Social Preferences, Financial Literacy and Intertemporal Choice
}

\author{
Sergio Da Silva ${ }^{1 *}$, Dinorá De Faveri ${ }^{1}$, Ana Correa1, Raul Matsushita² \\ ${ }^{1}$ Department of Economics, Federal University of Santa Catarina, Florianopolis, Brazil \\ ${ }^{2}$ Department of Statistics, University of Brasilia, Brasilia, Brazil \\ Email: *professorsergiodasilva@gmail.com
}

How to cite this paper: Da Silva, S., De Faveri, D., Correa, A. and Matsushita, R. (2017) Social Preferences, Financial Literacy and Intertemporal Choice. Open Access Library Journal, 4: e3699.

https://doi.org/10.4236/oalib.1103699

Received: May 31, 2017

Accepted: June 10, 2017

Published: June 13, 2017

Copyright (c 2017 by authors and Open Access Library Inc.

This work is licensed under the Creative

Commons Attribution International License (CC BY 4.0).

http://creativecommons.org/licenses/by/4.0/

(c) (i) Open Access

\begin{abstract}
We evaluate the relationship between social preferences, financial literacy and intertemporal choice in questionnaires distributed to university students. Most respondents perform well on a financial literacy test, and the majority show prosocial value orientation. Older students tend to be more prosocial, but we cannot confirm in our sample that females are more prosocial than males. We cannot confirm, either, that the prosocial are more financially literate than individualists and the competitive. Most respondents do not show hyperbolic discounting, and its incidence abates as both stakes and payoff delays increase. Prosocial participants also reveal to be more patient across the questionnaires.
\end{abstract}

\section{Subject Areas}

Behavioral Economics

\section{Keywords}

Social Preferences, Social Value Orientation, Financial Literacy, Intertemporal Choice, Hyperbolic Discounting, Impatience

\section{Introduction}

We study the interplay between social preferences, financial literacy and intertemporal choice using a sample of university students. We also consider the role played by the demographics of age, sex, income and savings.

There is neuroscientific evidence that people consider future versions of themselves as other people. Intertemporal choice is then about the interaction between multiple selves and other-regarding preferences influence decisions that involve discounting the future [1] [2]. Brain areas recruited when imagining oneself in the future (called "prospection") are the same as those recruited when 
mentalizing about other people (known as "theory of mind"). The same neural network-medial prefrontal, medial-temporal, medial and lateral parietal, lateral prefrontal and occipital cortices-is shared by both prospection and theory of mind [3].

To model other-regarding preferences we consider the approach known as Social Value Orientation [4] [5] [6], which acknowledges stable preference patterns of outcomes for oneself and others. Social Value Orientation (SVO) is a psychologically richer framework that generalizes the assumption of narrow self-interest. In particular, we take the "slider measure" of SVO, where people can be individualistic, competitive, prosocial and altruistic. These are their primary motivations. Individualistic people maximize their self-payoff; prosocial people maximize the joint payoff or minimize the difference between payoffs; competitive people maximize the positive difference between self-payoff and the other's payoff; and altruistic people maximize the other's payoff. The secondary motivations are: sadistic, masochistic, sadomasochistic and martyr. Sadistic people minimize the other's payoff; the masochistic minimizes the self-payoff; the sadomasochistic minimizes the joint payoff or minimizes the difference between payoffs; and the martyr maximizes the negative difference between the other's payoff and self-payoff [5] (Figure 1). SVO is related to cognition and thus behavior. In particular, it alters negotiation settings [7]; resource dilemmas [8]; the propensity to cooperate [9] and many other behaviors [10].

Intertemporal decisions-such as retirement plans-critically also depend on financial literacy [11]. This study thus considers financial literacy as a factor me-

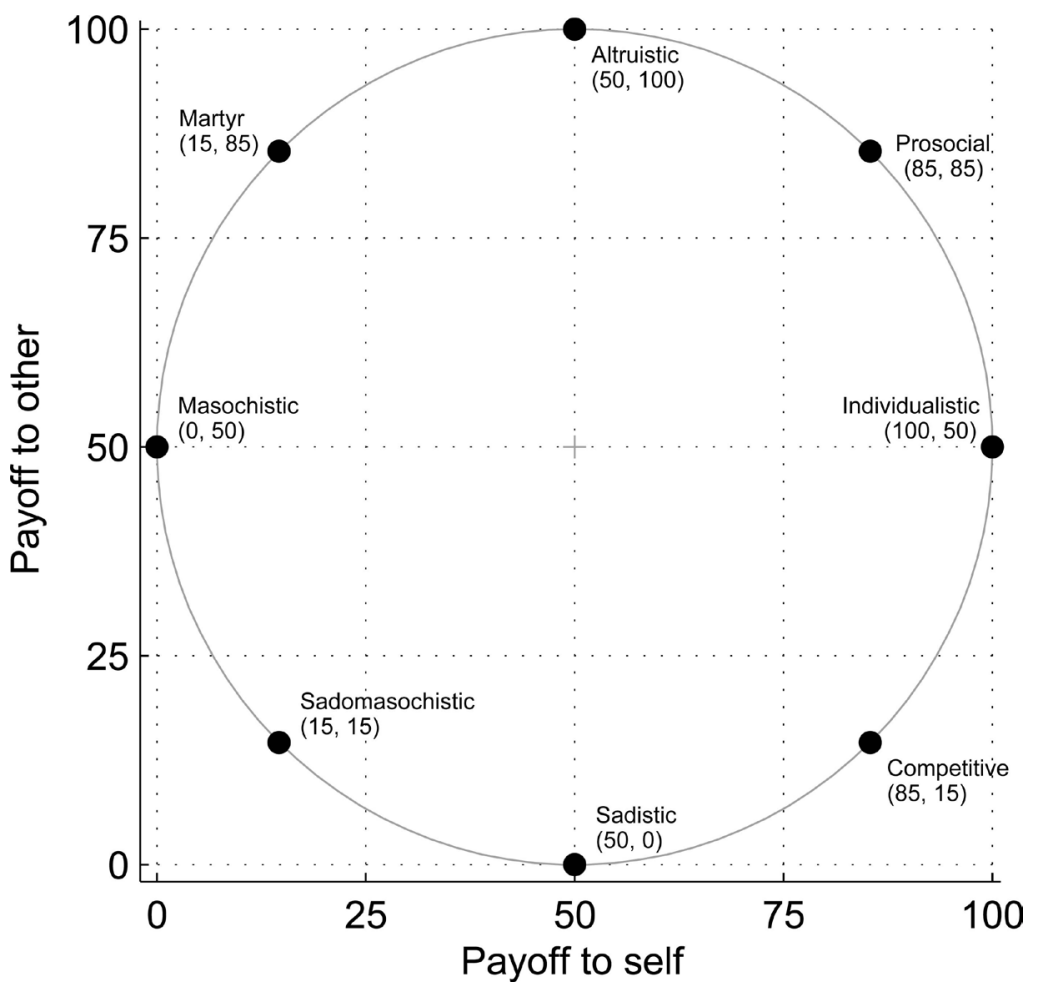

Figure 1. The self-other allocation plane for the primary and secondary Social Value Orientations [5]. Courtesy of Ryan O. Murphy. 
diating intertemporal decisions. We also consider the demographics of age, sex, income and savings to evaluate how these are related to social preferences and intertemporal choice. In the literature, behavior-such as risk-taking-depends on age [12]. Neurological differences between 25 year olds and 75 year olds are not noticeable. However, those who are ages 10 to 25 cannot accurately perceive risks, because hormones drive a need to impress peers by reckless behavior. Sensation-seekers present high testosterone [13] and low monoamine oxidase levels, which affect serotonin and mood. Thus, the hormonal differences of those below 25 years old can influence their other-regarding preferences and their attitudes toward intertemporal choice as well as risk-taking. An individual's sex also matters for risk-taking [14] and thus possibly for intertemporal discounting. Income and savings may be related to intertemporal choice through the mediation of cognitive aspects. For instance, high-income bank customers are less hyperbolic when discounting the future [15].

The rest of this paper is organized as follows. The materials and methods are presented in the next section. Section 3 presents the results found and contrasts them with the literature. Section 4 concludes the study.

\section{Materials and Methods}

The SVO Slider Measure is a choice task, as in Figure 2 [4] [5]. Each item is a resource allocation choice over a continuum of joint payoffs. A respondent picks his or her allocation choice by marking a line at the point that defines his most-preferred joint distribution. Then, he or she writes to the right of the item the corresponding payoffs resulting from his or her choice. The mean allocation for self $\bar{A}_{s}$ and for the other $\bar{A}_{o}$ is computed from all the six items in Figure 2. Then, 50 is subtracted from $\bar{A}_{s}$ and $\bar{A}_{o}$ to shift the base of the resulting angle to the center of the circle $(50,50)$. The index of a respondent's SVO is then:

$$
\mathrm{SVO}^{\circ}=\arctan \frac{\bar{A}_{o}-50}{\bar{A}_{s}-50}
$$

Depending on the value generated from the test in Figure 2, the SVO allocations define the social preferences as follows:

$$
\begin{aligned}
& \text { Altruism: } \mathrm{SVO}^{\circ}>57.15^{\circ} \\
& \text { Prosociality: } 22.45^{\circ}<\mathrm{SVO}^{\circ}<57.15^{\circ} \\
& \text { Individualism: }-12.04^{\circ}<\mathrm{SVO}^{\circ}<22.45^{\circ} \\
& \text { Competitiveness: } \mathrm{SVO}^{\circ}<-12.04^{\circ}
\end{aligned}
$$

We consider only the primary SVO allocations, as in Figure 3, because these ended up relevant for the answers we received from our study's questionnaires.

The financial literacy quiz is as follows.

1) Suppose you have $\$ 100$ in a savings account earning 2 percent interest a year. After five years, how much would you have?

( ) more than $\$ 102$

( ) exactly $\$ 102$ 


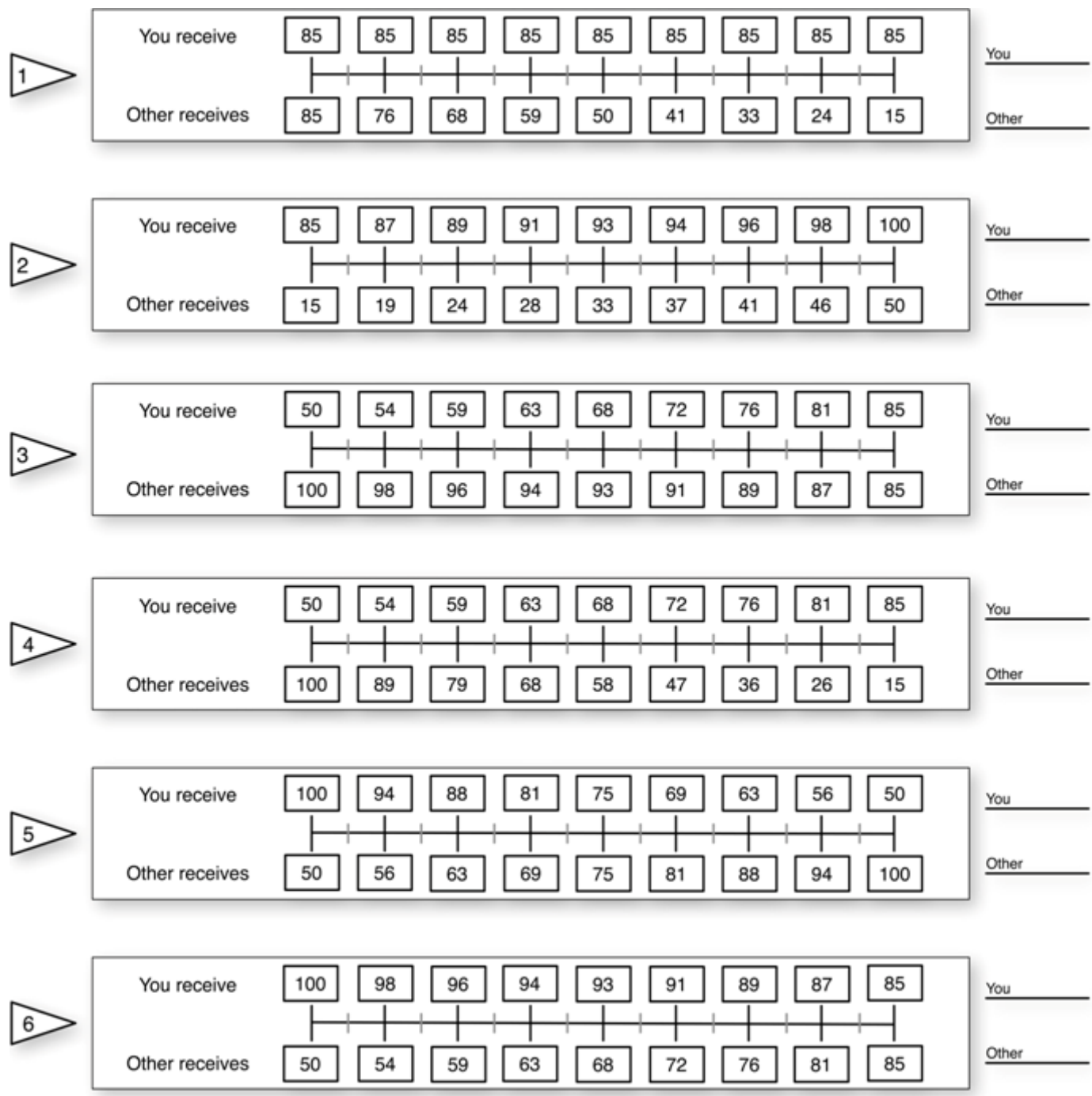

Figure 2. Test showing the SVO Slider items [4]. Courtesy of Ryan O. Murphy.

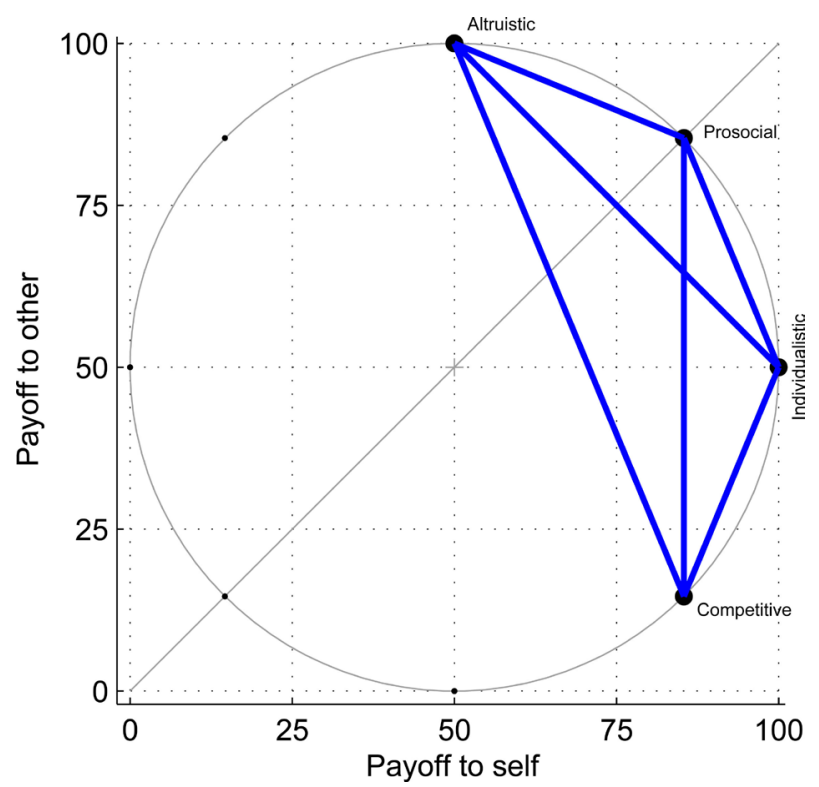

Figure 3. The self-other allocation plane for the primary Social Value Orientations [4]. Courtesy of Ryan O. Murphy. 
( ) less than $\$ 102$

() don't know

[Correct answer: "more than \$102"]

2) Imagine that the interest rate on your savings account is 1 percent a year and inflation is 2 percent a year. After one year, would the money in the account buy more than it does today, exactly the same or less than today?

( ) more

( ) same

( ) less

( ) don't know

[Correct answer: "less"]

3) A 15-year mortgage typically requires higher monthly payments than a 30-year mortgage, but the total interest over the life of the loan will be less.

( ) true

( ) false

( ) don't know

[Correct answer: "true"]

The three questions above were taken from the five-question Financial Literacy Quiz of the FINRA Investor Education Foundation

(www.usfinancialcapability.org/quiz.php). The first two questions refer to compound interest and inflation and evaluate whether respondents command key economic concepts fundamental to saving [11]. The third question refers to the crucial decision of home financing.

We gauge hyperbolic discounting through a questionnaire [16] where respondents are asked to choose between two sure payoffs at two distinct points in time: an early payoff and a later payoff. The participants are presented eight choice lists, each containing 10 questions. In a list, the early payoff remains the same and the later payoff is increased monotonically (Figure 4). The lists differ by the size of the stake of the early payoff (either 100 or 250) and by the timing of the early and late payoffs, as in Figure 5.

We calculate the "future equivalent" of the (fixed) early payoff from the eight lists as the midpoint between the two later payoffs, where a respondent switches from the earlier to the later payoff. Figure 6 shows how to compute the future equivalent for List 1 . The participant chose the payoff today twice (left-side option) and then switched to the right-side option. This means her future equivalent was $R \$ 107,50$, that is, $(R \$ 105,00+R \$ 110,00) / 2$. ( $R \$$ are the Brazilian real.) The larger the future equivalent, the stronger the delay aversion and impatience.

Of note, Lists 1 and 2 refer to identical delays (of three weeks) with an upfront delay of zero and three weeks respectively. In Lists 3 and 4, the delay is one year and the upfront delay is zero and three weeks, respectively. To know whether discounting is constant or not, we compare the future equivalents between such lists. If future equivalents are higher for List 1 than for List 2, and for List 3 than for List 4 , the early payoff receives more weight than the payoff in three weeks. 
List 1

[1] receive $R \$ 100,00$ now $O$ or Oreceive $R \$ 100,00$ in 3 weeks

[2] receive $R \$ 100,00$ now $O$ or Oreceive $R \$ 105,00$ in 3 weeks

[3] receive $R \$ 100,00$ now $O$ or Oreceive $R \$ 110,00$ in 3 weeks

[10] receive $\mathrm{R} \$ 100,00$ now $Q$ or Oreceive $\mathrm{R} \$ 145,00$ in 3 weeks

\section{List 2}

[11] receive $R \$ 100,00$ in 3 weeks $O$ or O receive $R \$ 100,00$ in 6 weeks

[12] receive $R \$ 100,00$ in 3 weeks $O$ or $O$ receive $R \$ 105,00$ in 6 weeks

[13] receive $R \$ 100,00$ in 3 weeks $O$ or $O$ receive $R \$ 110,00$ in 6 weeks

[20] receive $R \$ 100,00$ in 3 weeks $O$ or $O$ receive $R \$ 145,00$ in 6 weeks

\section{List 3}

[21] receive $R \$ 100,00$ now $O$ oro receive $R \$ 100,00$ in 1 year

[22] receive $R \$ 100,00$ now $O$ or $\bigcirc$ receive $R \$ 105,00$ in 1 year

[23] receive $\mathrm{R} \$ 100,00$ now $O$ oro receive $\mathrm{R} \$ 110,00$ in 1 year

[30] receive $R \$ 100,00$ now $O$ or 0 receive $R \$ 145,00$ in 1 year

List 4

[31] receive $R \$ 100,00$ in 3 weeks $O$ or Oreceive $R \$ 100,00$ in 1 year and 3 weeks [32] receive $R \$ 100,00$ in 3 weeks $Q$ or $Q$ receive $R \$ 105,00$ in 1 year and 3 weeks [33] receive $R \$ 100,00$ in 3 weeks $O$ or Oreceive $R \$ 110,00$ in 1 year and 3 weeks

[40] receive $R \$ 100,00$ in 3 weeks $O$ or $O$ receive $R \$ 145,00$ in 1 year and 3 weeks
List 5

[41] receive $R \$ 250,00$ now $O$ or Oreceive $R \$ 250,00$ in 3 weeks

[42] receive $R \$ 250,00$ now $O$ or Oreceive $R \$ 275,00$ in 3 weeks

[43] receive $R \$ 250,00$ now $O$ or Oreceive $R \$ 300,00$ in 3 weeks

…........

[50] receive $\mathrm{R} \$ 250,00$ now $Q$ or $O$ receive $\mathrm{R} \$ 475,00$ in 3 weeks

\section{List 6}

[51] receive $R \$ 250,00$ in 3 weeks $O$ or Oreceive $R \$ 250,00$ in 6 weeks

[52] receive $R \$ 250,00$ in 3 weeks 0 or 0 receive $R \$ 275,00$ in 6 weeks

[53] receive $R \$ 250,00$ in 3 weeks $O$ or Oreceive $R \$ 300,00$ in 6 weeks

[60] receive $\mathrm{R} \$ 250,00$ in 3 weeks $\bigcirc$ or $O$ receive $R \$ 475,00$ in 6 weeks

List 7
[61] receive $R \$ 250,00$ now $O$ or $O$ receive $R \$ 250,00$ in 1 year
[62] receive $R \$ 250,00$ now $O$ or $O$ receive $R \$ 275,00$ in 1 year
[63] receive $R \$ 250,00$ now $O$ or $O$ receive $R \$ 300,00$ in 1 year
[7.....
[70] receive $R \$ 250,00$ now $O$ or $O$ receive $R \$ 475,00$ in 1 year

List 8
[71] receive $R \$ 250,00$ in 3 weeks $\bigcirc$ or $O$ receive $R \$ 250,00$ in 1 year and 3 weeks
[72] receive $R \$ 250,00$ in 3 weeks $\bigcirc$ or $\bigcirc$ receive $R \$ 275,00$ in 1 year and 3 weeks
[72] receive $R \$ 250,00$ in 3 weeks $\bigcirc$ or $\bigcirc$ receive $R \$ 300,00$ in 1 year and 3 weeks
$\ldots \ldots \ldots .$.
[80] receive $R \$ 250,00$ in 3 weeks $\bigcirc$ or $O$ receive $R \$ 475,00$ in 1 year and 3 weeks

Figure 4. Gauging hyperbolic discounting using choice lists. Adapted from Sutter et al. [16].

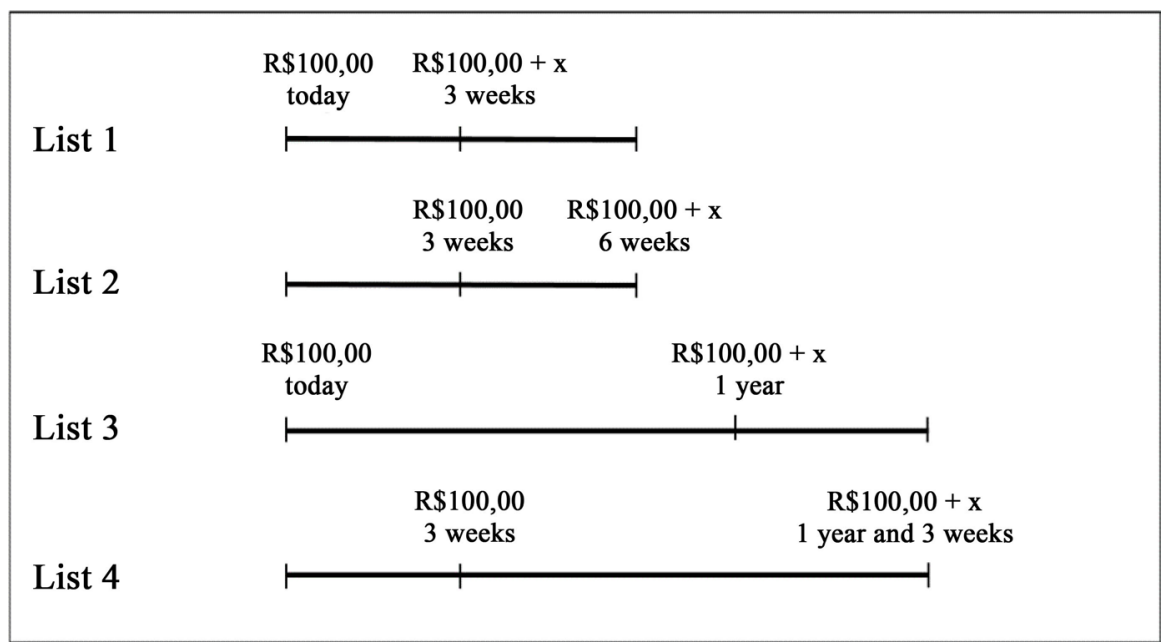

Figure 5. Combinations of early and late payoffs (four lists for a sure payoff of 100). Adapted from Sutter et al. [16].

\section{List 1 \\ [1] receive $\mathrm{R} \$ 100,00$ now $O$ or $O$ receive $\mathrm{R} \$ 100,00$ in 3 weeks [2] receive $\mathrm{R} \$ 100,00$ now $O$ or $O$ receive $R \$ 105,00$ in 3 weeks [3] receive $\mathrm{R} \$ 100,00$ now $\mathrm{O}$ or $\bigcirc$ receive $\mathrm{R} \$ 110,00$ in 3 weeks}

Figure 6. Example of calculation of the future equivalent for List 1. Adapted from Sutter et al. [16].

This would provide evidence of hyperbolic discounting. We can further control for the effects of stake size by considering these four timing combinations for both high and low stakes (as in Figure 4).

After computing the future equivalents of each list in Figure 4, the lists can be compared in pairs. Considering the delays (three weeks or one year) and stakes 
Table 1. Four types of hyperbolic discounting measured by future equivalents, considering delays and stakes.

\begin{tabular}{ccc}
\hline & \multicolumn{2}{c}{ Delay } \\
\hline Stake & 3 weeks & 1 year \\
Low & Type-1 hyperbolic discounting & Type-2 hyperbolic discounting \\
High & Type-3 hyperbolic discounting & Type-4 hyperbolic discounting \\
\hline
\end{tabular}

(100 or 250), four types of hyperbolic discounting can thus be measured (Table 1). If the future equivalent in List 1 is, say, greater than that in List 2 , this means the early payoff is weighted more than the payoff in three weeks. This would reveal a "present bias," in this case a hyperbolic discounting of Type 1. Comparing Lists 3 and 4 yields a Type-2 hyperbolic discounting, and so on.

From the computations of future equivalents for the eight lists, "implicit annual discount rates" [16], $i$, can be calculated as

$$
i=\ln \left(\frac{\text { future equivalent }}{\text { early payoff }}\right)
$$

for a one-year delay (assuming continuous discounting), and

$$
i=\ln \left(\frac{\text { future equivalent }}{\text { early payoff }}\right) \frac{52}{3}
$$

for delay of three weeks, as a year has 52 weeks.

Participants from both sexes filled out the eight lists in Figure 4 in a random order. All participants were asked whether their age was below 25, or equal to 25 or above. This is claimed to be a useful sorting of age groups from a neural perspective, as observed. Participants also reported their monthly income in the Brazilian real, whether below $\mathrm{R} \$ 1000$; between $\mathrm{R} \$ 1000$ and $\mathrm{R} \$ 10,000$; or above $\mathrm{R} \$ 10,000$. We also asked the participants what the share of their income, if any, usually was left for savings (none; less than 10 percent; more than 10 percent).

We collected a sample of 419 university students from accounting, pedagogy, economics, management and psychology from higher education institutions of the Santa Catarina, a state in Brazil. The universities were UFSC, UDESC, UNIASSELVI, FUCAP and UNISUL, located in the municipalities of Florianopolis, Indaial, Ibirama, Tubarão and Capivari de Baixo. We dropped from the sample 63 participants whose questionnaires were incomplete or incongruent and thus, our sample ended up with 356 valid questionnaires. After a pilot experiment on 21 September 2016, the questionnaires were distributed between 28 September 2016 and 22 November 2016. The experiment was registered at Plataforma Brasil under No. 64758617.2.0000.0121, a Brazilian government organization that assesses the ethical proceedings of experiments that include human beings. The dataset is available at Figshare (https://doi.org/10.6084/m9.figshare.5036177.v2).

\section{Results and Discussion}

Of the 356 participants, 59.6 percent were females; 76.7 percent younger than 25; 59.3 percent had incomes between 1000 and 10,000 reais a month; and 40.2 per- 
Table 2. Continuous SVO.

\begin{tabular}{cccccc}
\hline & Mean & Median & Std Dev & Minimum & Maximum \\
\hline SVO $^{\circ}$ & 19.67 & 21.74 & 15.58 & $-16.26^{\circ}$ & $45.83^{\circ}$ \\
\hline
\end{tabular}

cent saved more than 10 percent of their monthly income. As expected of undergraduates, most participants performed well on the financial literacy quiz (82.3, 63.5 and 66.6 percent correctly answered questions 1,2 and 3 respectively). As for their social value orientation, 49.4 percent were prosocial; 47.8 percent were individualistic; 2.8 percent were competitive; and no one was altruistic. This agrees with the literature using students and the general population, where most people are prosocial [17] [2] [4] [18] [10]. Table 2 shows the results for the SVO angles' values $\left(\right.$ mean $=19.67^{\circ}$; standard deviation $\left.=15.58^{\circ}\right)$. Considering the value of the median, half the students showed an angle greater than $21.74^{\circ}$.

In agreement with the literature [10], older students (ages 25 and above) were more prosocial (Spearman correlation $\rho=0.149, p$-value $=0.005 ; \chi^{2}=7.868$, $p$-value $=0.02)$. In the literature, females are more prosocial than males [10]. However, in our sample there is no guarantee this is true (Spearman correlation $\rho=0.004, p$-value $=0.942 ; \chi^{2}=0.491, p$-value $\left.=0.782\right)$. University females as a group are possibly different from the group of females in general.

In the literature, one can expect the prosocial group is relatively more financially literate than the individualist and the competitive groups. This is so because those with superior financial literacy usually make plans and save more [11], and those who take better care of their future well-being [2] and are more patient [19] tend to be prosocial. However, in our sample that is not necessarily true. We failed to significantly find that the prosocial beat the others (individualists and the competitive) regarding the financial literacy questionnaire (Spearman correlation $\rho=0.039, p$-value $=0.466 ; \chi^{2}(3)=0.781, p$-value $=$ $0.854)$.

Most participants did not show hyperbolic discounting (Figure 7). This is not unexpected and agrees with the literature [20]. However, for those affected by the present bias, Figure 7 suggests the incidence of hyperbolic discounting is abated as both stakes and payoff delays increased. As for stake size, our results thus confirmed the existence in our sample of a "magnitude effect" [21]. That is, participants were sensitive not only to the relative differences in money amounts, but also to the absolute differences.

The computation of the implicit discount rates allowed us to uncover that the prosocial were more patient in our sample (Table 3). Apart from List 3 (which did not show statistical significance), a negative correlation was found between prosocial SVO and impatience. This result was also in line with the literature [2] [19] [22].

\section{Conclusion}

We considered the relationship between social preferences, financial literacy and 


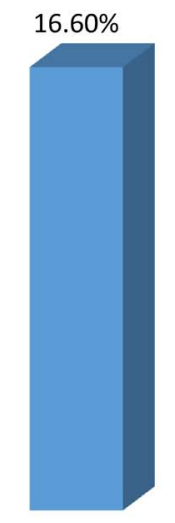

Type 1

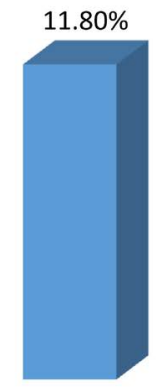

Type 2

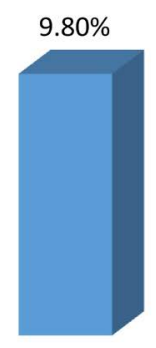

Type 3

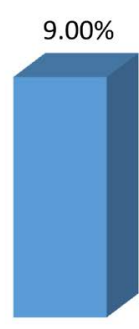

Type 4

Figure 7. Incidence of hyperbolic discounting, by type.

Table 3. Spearman correlation between prosocial SVO and impatience.

\begin{tabular}{ccccc}
\hline & List 1 & List 3 & List 5 & List 7 \\
\hline$\rho$ & -0.119 & -0.056 & -0.130 & -0.119 \\
$p$-value & 0.024 & 0.289 & 0.013 & 0.024 \\
\hline
\end{tabular}

intertemporal choice in a validated sample of 356 university students. Most participants performed well on a financial literacy quiz, and the majority showed prosocial value orientation. Those ages 25 and older tended to be more prosocial, but we could not confirm the literature finding that females are more prosocial than males. Possibly in contrast with the literature, too, we failed to significantly find that the prosocial group beats individualists and the competitive group regarding financial literacy. Most participants did not show hyperbolic discounting. However, for those showing hyperbolic discounting, its incidence is abated as both stakes and payoff delays increased. Thus, a "magnitude effect" appeared in our sample. The prosocial were also more patient-a result that is in line with the literature.

\section{References}

[1] Jamison, J. and Wegener, J. (2010) Multiple Selves in Intertemporal Choice. Journal of Economic Psychology, 31, 832-839. https://doi.org/10.1016/j.joep.2010.03.004

[2] Da Silva, S., Matsushita, R. and De Carvalho, M. (2015) Prosocial People Take Better Care of Their Own Future Well-Being. Open Access Library Journal, 2, e2181. https://doi.org/10.4236/oalib.1102181

[3] Spreng, R.N., Mar, R.A. and Kim, A.S.N. (2009) The Common Neural Basis of Autobiographical Memory, Prospection, Navigation, Theory of Mind and the Default Mode: A Quantitative Meta-Analysis. Journal of Cognitive Neuroscience, 21, 489510. https://doi.org/10.1162/jocn.2008.21029

[4] Murphy, R.O., Ackermann, K.A. and Handgraaf, M.J.J. (2011) Measuring Social Value Orientation. Judgment and Decision Making, 6, 771-781.

[5] Murphy, R.O. and Ackermann, K.A. (2011) A Review of Measurement Methods for 
Social Preferences. ETH Zurich Chair of Decision Theory and Behavioral Game Theory Working Paper.

[6] Nax, H.H., Murphy, R.O. and Ackermann, K.A. (2015) Interactive Preferences. Economics Letters, 135, 133-136. https://doi.org/10.1016/j.econlet.2015.08.008

[7] De Dreu, C.K.W. and Boles, T.L. (1998) Share and Share Alike or Winner Take All?: The Influence of Social Value Orientation upon Choice and Recall of Negotiation Heuristics. Organizational Behavior and Human Decision Processes, 76, 253-276. https://doi.org/10.1006/obhd.1998.2806

[8] Roch, S.G., Lane, J.A.S., Samuelson, C.D., Allison, S.T. and Dent, J.L. (2000) Cognitive Load and the Equality Heuristic: A Two-Stage Model of Resource Overconsumption in Small Groups. Organizational Behavior and Human Decision Processes, 83, 185-212. https://doi.org/10.1006/obhd.2000.2915

[9] Zeelenberg, M., Nelissen, R.M.A., Breugelmans, S.M. and Pieters, R. (2008) On Emotion Specificity in Decision Making: Why Feeling Is for Doing. Judgment and Decision Making, 3, 18-27.

[10] Van Lange, P.A.M., De Bruin, E.M.N., Otten, W. and Joireman, J.A. (1997) Development of Prosocial, Individualistic, and Competitive Orientations: Theory and Preliminary Evidence. Journal of Personality and Social Psychology, 73, 733-746. https://doi.org/10.1037/0022-3514.73.4.733

[11] Lusardi, A. and Mitchell, O.S. (2011) Financial Literacy and Planning: Implications for Retirement Wellbeing. NBER Working Paper No. 17078.

[12] Moreira, B., Matsushita, R. and Da Silva, S. (2010) Risk Seeking Behavior of Preschool Children in a Gambling Task. Journal of Economic Psychology, 31, 794-801. https://doi.org/10.1016/j.joep.2010.03.005

[13] Campbell, B.C., Dreber, A., Apicella, C.L., Eisenberg, D.T., Gray, P.B., Little, A.C., Garcia, J.R., Zamore, R.S. and Lum, J.K. (2010) Testosterone Exposure, Dopaminergic Reward, and Sensation-Seeking in Young Men. Physiology \& Behavior, 99, 451-456. https://doi.org/10.1016/j.physbeh.2009.12.011

[14] Eckel, C.C. and Grossman, P.J. (2008) Men, Women and Risk Aversion: Experimental Evidence. In: Plott, C. and Smith, V., Eds., Handbook of Experimental Economics Results, Vol. 1, Elsevier, New York, 1061-1073. https://doi.org/10.1016/S1574-0722(07)00113-8

[15] Da Silva, S., De Faveri, D., Correa, A. and Matsushita, R. (2017) High-Income Consumers May Be Less Hyperbolic When Discounting the Future. (Unpublished)

[16] Sutter, M., Kocher, M.G., Glätzle-Rüetzler, D. and Trautmann, S.T. (2013) Impatience and Uncertainty: Experimental Decisions Predict Adolescents' Field Behavior. American Economic Review, 103, 510-531.

[17] Liebrand, W.B.G. and McClintock, C.G. (1988) The Ring Measure of Social Values: A Computerized Procedure for Assessing Individual Differences in Information Processing and Social Value Orientation. European Journal of Personality, 2, 217-230. https://doi.org/10.1002/per.2410020304

[18] Liebrand, W.B.G. (1984) The Effect of Social Motives, Communication and Group Size on Behaviour in an $n$-Person Multi-Stage Mixed-Motive Game. European Journal of Social Psychology, 14, 239-264. https://doi.org/10.1002/ejsp.2420140302

[19] Balliet, D. and Joireman, J. (2010) Ego Depletion Reduces Proselfs' Concern with the Well-Being of Others. Group Processes \& Intergroup Relations, 13, 227-239. https://doi.org/10.1177/1368430209353634

[20] Frederick, S., Loewenstein, G. and O’Donoghue, T. (2002) Time Discounting and Time Preference: A Critical Review. Journal of Economic Literature, 40, 351-401. 
[21] Prelec, D. and Loewenstein, G. (1991) Decision Making over Time and under Uncertainty: A Common Approach. Management Science, 37, 770-786.

https://doi.org/10.1287/mnsc.37.7.770

[22] Bartels, D.M. and Urminsky, O. (2011) On Intertemporal Selfishness: How the Perceived Instability of Identity Underlies Impatient Consumption. Journal of Consumer Research, 38, 182-198. https://doi.org/10.1086/658339

Submit or recommend next manuscript to OALib Journal and we will provide best service for you:

- Publication frequency: Monthly

- 9 subject areas of science, technology and medicine

- Fair and rigorous peer-review system

- Fast publication process

- Article promotion in various social networking sites (LinkedIn, Facebook, Twitter, etc.)

- Maximum dissemination of your research work

Submit Your Paper Online: Click Here to Submit

Or Contact service@oalib.com 